\title{
MGMT, GATA6, CD81, DR4, and CASP8 gene promoter methylation in glioblastoma
}

\author{
Daina Skiriute ${ }^{1 *}$, Paulina Vaitkiene ${ }^{1}$, Viktoras Saferis ${ }^{2}$, Virginija Asmoniene ${ }^{1}$, Kestutis Skauminas ${ }^{1}$, \\ Vytenis Pranas Deltuva ${ }^{1}$ and Arimantas Tamasauskas ${ }^{1}$
}

\begin{abstract}
Background: Methylation of promoter region is the major mechanism affecting gene expression in tumors. Recent methylome studies of brain tumors revealed a list of new epigenetically modified genes. Our aim was to study promoter methylation of newly identified epigenetically silenced genes together with already known epigenetic markers and evaluate its separate and concomitant role in glioblastoma genesis and patient outcome.
\end{abstract}

Methods: The methylation status of MGMT, CD81, GATA6, DR4, and CASP8 in 76 patients with primary glioblastomas was investigated. Methylation-specific PCR reaction was performed using bisulfite treated DNA. Evaluating glioblastoma patient survival time after operation, patient data and gene methylation effect on survival was estimated using survival analysis.

Results: The overwhelming majority (97.3\%) of tumors were methylated in at least one of five genes tested. In glioblastoma specimens gene methylation was observed as follows: MGMT in 51.3\%, GATA6 in 68.4\%, CD81 in 46.1\%, DR4 in $41.3 \%$ and CASP8 in 56.8\% of tumors. Methylation of MGMT was associated with younger patient age $(p<0.05)$, while CASP8 with older $(p<0.01)$. MGMT methylation was significantly more frequent event in patient group who survived longer than 36 months after operation $(p<0.05)$, while methylation of CASP8 was more frequent in patients who survived shorter than 36 months $(p<0.05)$. Cox regression analysis showed patient age, treatment, MGMT, GATA6 and CASP8 as independent predictors for glioblastoma patient outcome $(p<0.05)$. MGMT and GATA6 were independent predictors for patient survival in younger patients' group, while there were no significant associations observed in older patients' group when adjusted for therapy.

Conclusions: High methylation frequency of tested genes shows heterogeneity of glioblastoma epigenome and the importance of MGMT, GATA6 and CASP8 genes methylation in glioblastoma patient outcome.

Keywords: MGMT, CD81, GATA6, DR4, CASP8, DNA methylation, MSP, Glioblastoma, Survival

\section{Background}

Glioblastoma is the most common and aggressive astrocytic tumor of the central nervous system in adults. It is characterized by various genetic alterations, affecting genes that control cell growth, apoptosis, angiogenesis, and invasion. Epigenetic alterations also affect the expression of cancer genes alone or in combination with genetic mechanisms. Cytosine methylation of $\mathrm{CpG}$ dinucleotides in gene promoters is a common cause of DNA

\footnotetext{
* Correspondence: dainski@gmail.com

'Laboratory of Neurooncology and Genetics, Neuroscience Institute, Medical Academy, Lithuanian University of Health Sciences, Eiveniu str. 4, Kaunas, LT 50009, Lithuania

Full list of author information is available at the end of the article
}

silencing and transcriptional repression that can modulate clinical features of globlastoma. The best known is $\mathrm{O}^{6}$-methylguanine-DNA methyltransferase (MGMT) promoter methylation determining tumors response to DNA alkylating agents and being an independent prognostic factor for patient survival [1]. However, several widely described genes can be seen as only a partial picture of the methylation changes, there may be many more genes that need to be clarified. Recent methylome studies of brain tumors have disclosed a list of new epigenetically modified genes associated with gliomagenesis and different glioma clusters [2-4]. The latter studies illustrate glioblastoma profile being constructed via methylation of a multiple set of genes, forming networks 
attributed to different pathogenesis pathways. It has been suggested that in glioblastoma, highly methylated genes, such as CD81 (CD81 antigen), DR4 (death receptor 4, TRAIL receptor 1) and GATA6 (GATA binding protein 6), participating in cell adhesion, apoptosis, and proliferation [3] could be important in gliomagenesis. Newly obtained influence of GATA6 hypermethylation on glioblastoma patient survival in a small group of tumors was shown as a promising marker in prognostic purposes [3]. To further study the importance of promoter methylation of newly identified epigenetically silenced genes (GATA6, CD81) and revealing its relationship with already known epigenetic markers (MGMT, DR4, CASP8 (caspase-8)) could help to better understand glioblastoma biology. In the first part of the study we have reported promoter methylation of MGMT, GATA6, CD81, DR4, and CASP8 genes. In the second part we have analyzed gene methylation correlations with patient variables. And in the third part we have analyzed whether the methylation status of five genes separately or in clusters are independent predictors for patient outcome.

\section{Methods}

\section{Patient sample}

The methylation profile of the MGMT, GATA6, CD81, $D R 4$, and CASP8 genes in 76 patients with WHO grade IV glioblastomas was investigated. All glioblastomas were graded and classified according to the $2007 \mathrm{WHO}$ classification criteria [5]. Tissue samples were collected from the Department of Neurosurgery, Hospital of Lithuanian University of Health Sciences Kaunas Clinics, from 2003 to 2009. The ethics committee of Lithuanian University of Health Sciences and the Lithuanian Bioethics Committee approved the collection and use of human brain tumor tissue samples. Written informed consent was obtained from all patients before the surgery. Survival time was collected for all cases and calculated from the time of surgery to death or censor.

\section{Methylation-specific PCR}

Brain tumor tissue specimens after dissection were snap-frozen and stored in liquid nitrogen until analysis. Tumor DNA was extracted using ZR Genomic DNA Tissue MiniPrep (Zymo Research, USA) from 25-40 mg of frozen tissue according to the manufacturer's instructions. The methylation status of MGMT, CD81, GATA6, $D R 4$, and CASP8 gene promoters was determined by bisulfite treatment of DNA. An amount of $400 \mathrm{ng}$ of DNA was used for bisulfite modification. DNA modification was done using the EZ DNA Methylation Kit (Zymo Research, USA), and all the procedures were carried out according to the manufacturer's protocol. Bisulfitetreated DNA was eluted in $40 \mu \mathrm{L}$ distilled water and stored in $-80{ }^{\circ} \mathrm{C}$ until PCR. Normal human blood lymphocyte DNA treated with bisulfite served as a negative control. As a positive control, standard Bisulfite Converted Universal Methylated Human DNA Standard (Zymo Research, USA) was used. Promoter methylation was detected by methylation-specific PCR (MSP). Each MSP reaction incorporated approximately $20 \mathrm{ng}$ of bisulfite-treated DNA as a template. Specific for methylated and unmethylated DNA sequence primers are listed in Table 1 and were obtained from published data (for MGMT [6], CD81 [7], GATA6 [8], DR4 [9], and CASP8 [10]). PCR reaction was performed in a total volume of 20 $\mu \mathrm{L}$, using $10 \mu \mathrm{L}$ Maxima ${ }^{\circledR}$ Hot Start PCR Master Mix with Hot Start Taq DNA polymerase (Thermo Fisher Scientific, USA) and $10 \mu \mathrm{M}$ of each primer (Metabion International AG, Germany). MSP was performed for 38-40 cycles with start of $95{ }^{\circ} \mathrm{C}$ for $1 \mathrm{~min}$, annealing for $1 \mathrm{~min}$ at temperature appropriate for an individual gene, and extension at $72{ }^{\circ} \mathrm{C}$ for $1 \mathrm{~min}$. Amplification products were loaded on $2 \%$ agarose gels with ethidium bromide and

Table 1 Primers for methylation-specific PCR

\begin{tabular}{|c|c|c|c|}
\hline Gene & Forward primer $5^{\prime}-3^{\prime}$ & Reverse primer $5^{\prime}-3^{\prime}$ & $\mathrm{Tm}$ \\
\hline MGMT-M & TTTCGACGTTCGTAGGTTTTCGC & GCACTCTTCCGAAAACGAAACG & 64 \\
\hline MGMT-U & TITGTGTTTGATGTTGGAAGGTTITGT & AACTCCACACTCTTCCAAAAACAAAACA & 62 \\
\hline CD81-M & CGACGGCGGCGATITATCGC & GACCTACGAAACGCGAACCG & 58 \\
\hline CD81-U & GTGATGGTGGTGATTITATTGT & ACAACCTACAAAACACAAACCAA & 58 \\
\hline GATA6-M & CGGGGTAGATTTCGGATTCGC & CAACCGAACCTCGAACGAACG & 60 \\
\hline GATA6-U & GTGTGGGGTAGATTTGGATTTGT & AAACAACCAAACCTCAAACAAACA & 60 \\
\hline$\overline{D R 4-M}$ & TTCGAATTTCGGGAGCGTAGC & GTAATTCAATCCTCCCCGCGA & 60 \\
\hline DR4-U & GTAGTGATTTGAATTITGGGAGTGTAGT & CTCATAATTCAATCCCCACAA & 60 \\
\hline CASP8-M & TAGGGGATTCGGAGATTGCGA & CGTATATCTACATTCGAAACGA & 58 \\
\hline CASP8-U & TAGGGGATTTGGAGATTGTGA & CCATATATATCTACATTCAAAACAA & 58 \\
\hline
\end{tabular}

$\mathrm{M}=$ methylated, $\mathrm{U}=$ unmethylated, $\mathrm{Tm}=$ melting temperature. 
after electrophoresis documented under UV. In a case of both, methylated and unmethylated signals appearance in a gel, methylation of the gene was considered.

\section{Statistical analysis}

Statistical analysis was carried out with the software of IBM SPSS Statistics 19 (IBM SPSS Inc., Chicago, IL). Quantitative data presented as mean and standard deviation (SD). To show the reliability of the estimate, the confidence interval (CI) with 95\% confidence level was presented. For testing the statistical hypothesis the significance level of 0.05 was selected. The Kaplan-Meier method was used to estimate survival functions. For comparison of survival between two groups, the log-rank and generalized Wilcoxon tests were used. The Cox proportional hazard regression model was applied to determine independent variables and prognosis relative hazard. For comparing means of two groups the independent samples $t$ test was used. For testing statistical hypothesis about the independence of two variables, the chi-square test was used.

\section{Results}

\section{Glioblastoma patient data}

The mean age at diagnosis was 61.2 years (range: 34-88; SD: 12.3 years). The male-to-female ratio was $1: 1.5$. The mean age of male $(n=30)$ and female $(n=46)$ patients was 59.9 years (SD: 13.3 years) and 62 years (SD: 11.6 years), respectively.

The mean survival of patients with glioblastoma ( $\mathrm{n}=76$ ) was 14.6 months (range: 0.26-52.60 months), while the median survival was 7.7 months (95\% CI: 4.81 10.6 months). The survival rate at 12 and 24 months was $34.2 \%$ (95\% CI: $23.7 \%-46.0 \%)$ and $22.4 \%$ (95\% CI: $13.6 \%-33.4 \%)$, respectively.
As expected, it was observed glioblastoma patient survival association with age and adjuvant treatment (logrank test, $P=0.001$ ). The median survival of patients aged $<60$ years and $\geq 60$ years was 15.6 and 4.5 months, respectively. Radiotherapy (RT) alone and RT plus concomitant chemotherapy (temozolomide) ( $\mathrm{TT}+\mathrm{TMZ}$ ) were used for the postoperative treatment of glioblastomas in our study. RT alone was administered in $85.3 \%(n=58)$ of cases and RT + TMZ was used in $14.7 \%(n=10)$ of cases. Eight patients did not receive postoperative treatment due to their critical condition. The median survival for patients treated with RT + TMZ versus RT alone was 42.2 months (95\% CI: 13.19-71.18 months) and 7.7 months (95\% CI: 4.34-11.04 months).

\section{Frequency of gene methylation and co-methylation in glioblastoma}

The overwhelming majority (97.3\%) of tumors were methylated in at least one of five genes tested. Only $2.7 \%$ of glioblastomas had no detectable gene methylation, and $4.1 \%$ had concomitant methylation of all five genes tested. Methylation frequencies were $51.3 \%(\mathrm{n}=76)$ for MGMT, $68.4 \%(\mathrm{n}=76)$ for GATA6, 46.1\% $(\mathrm{n}=76)$ for $C D 81,41.3 \% \quad(\mathrm{n}=75)$ for $D R 4$, and $56.0 \% \quad(\mathrm{n}=75)$ for CASP8. Representative methylation-specific PCR for the mentioned genes is illustrated in Figure 1.

Despite the frequent co-methylation of two genes in the same tissue varying from about $15 \%$ to $37 \%$, no significant associations in the frequencies of gene methylation were documented (chi-square test, $P>0.05$ ).

\section{Associations between gene methylation and co-methylation, and patient data}

Methylation of MGMT was associated with younger patient age at diagnosis (chi-square test, $P=0.039$ ), while

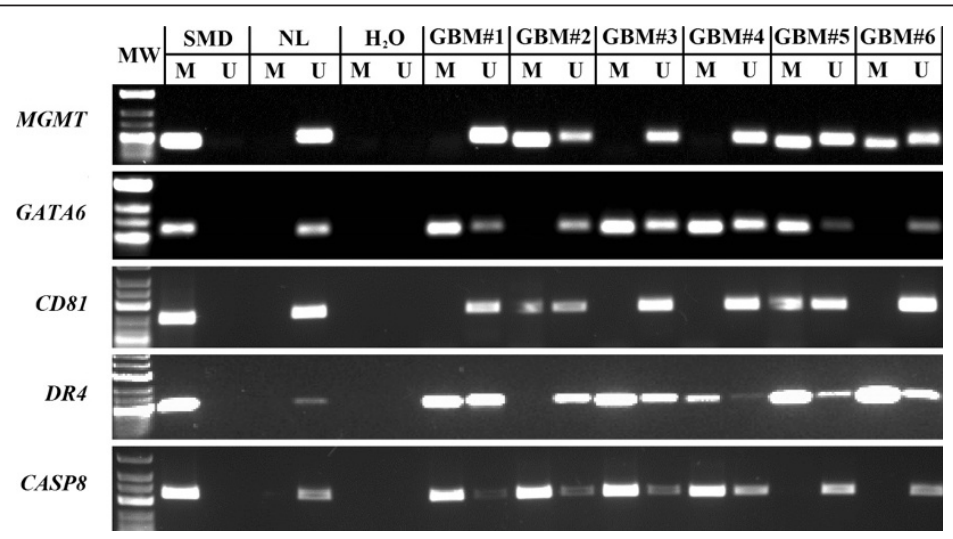

Figure 1 Representative methylation specific PCR reaction for MGMT, GATA6, CD81, DR4 and CASP8 genes. U represents amplification of unmethylated allele, and M represents methylated allele. Standard Bisulfite Converted Universal Methylated Human DNA (SMD) and normal human peripheral lymphocytes (NL) served as positive and negative methylation controls, respectively. MW - molecular weight. $\mathrm{H}_{2} \mathrm{O}-$ water control. GBM\#1 - 6 glioblastoma patient tumor samples. 
methylation of CASP8 more often was observed in older patients (chi-square test, $P=0.002$ ) (Table 2). When grouping patients according to survival time, it was shown that MGMT gene methylation was significantly more frequent event in patient group who survived longer than 36 months after diagnosis (chi-square test, $P=0.031$ and $P=0.006$, respectively), while CASP 8 and $D R 4$ gene methylation was more frequent event in patient group who survived up to 36 months (chi-square test, $P=0.035$ and $P=0.061$ respectively) (Table 2 ). GATA6 and CASP8 methylation in older patients were significantly associated with co-unmethylated MGMT (chi-square test, $P=0.021$ and $P=0.003$ respectively). Of the patients older than 60 years who lacked MGMT promoter methylation, $45.5 \%$ and $44.2 \%$ showed concomitant aberrant GATA6 and CASP8 methylation respectively. GATA6 methylation in older patients was significantly associated with co-methylated CASP8 and DR4 (28\% and $24.9 \%$, chi-square test, $P=0.005$ and $P=0.039$ respectively), as well as CASP8 methylation with co-methylated DR4 (34.9\%) (chi-square test, $P=0.017)$.

\section{Associations between gene methylation and patient survival}

Figure 2 shows the associations between the methylation of five gene promoters and patient survival. The methylation of the MGMT promoter was associated with longer survival (log-rank test, $P=0.005$ ) (Figure 2A). The median survival in the methylated and unmethylated MGMT groups was 9.9 months and 6.2 months, respectively (Table 3). The 12- and 24-month survival rates for methylated versus unmethylated MGMT cases were $46.2 \%$ (95\% CI: $30.1 \%-62.8 \%$ ) and $33.3 \%$ (95\% CI: $19.1 \%-50.2 \%$ ) versus $21.6 \%$ (95\% CI: $9.8 \%-38.2 \%)$ and 10.8\% (95\% CI: 3.0\%-25.4\%), respectively.

No significant associations between the methylation of GATA6, CD81, and DR4 and patient survival were identified (Figures 2B-D). However, analysis of patient survival at early postoperative period showed a significantly shorter survival among patients with the methylated GATA6 promoter (Wilcoxon test, $P=0.045$ ).

Contrary to the methylation profile of $M G M T$, the methylation of the CASP8 promoter was associated with shorter survival (log-rank test, $P=0.040$ ) (Figure $2 \mathrm{E}$ ). The median survival among patients with the unmethylated CASP8 promoter was 9.9 months (95\% CI: 6.9-12.9 month) as compared with 6.2 months (95\% CI: 3.3-9.2 months) among their counterparts with the methylated CASP8 promoter.

\section{Associations between gene co-methylation and patient survival}

Concomitant gene methylation effect on patient survival was done on genes significantly associated with survival in the univariate analysis. Kaplan-Meier analysis showed that not methylated MGMT in a case of methylated GATA6 and CASP8 were significantly associated with worse outcome (median survival - 3.8 months and 4.9 months, respectively) as compared to that of the patients whose tumors had methylated MGMT with unmethylated GATA6 and CASP8 (median survival 10.9 and 14.1 months respectively, log-rank test, $P=0.009$ and $P=0.003$ respectively), as well as tumors with no methylation of both genes (MGMT and GATA6) (median survival - 9.6 months, log-rank test, $P=0.043$ ), and tumors with double methylation (MGMT and CASP8, MGMT and GATA6, median survival -8.9 and 8.9 months, log-rank test, $P=0.019$ and $P=0.006$ respectively) (Figure 3A-B). Concomitant methylation status analysis of GATA6 and CASP8 showed the lowest median survival in a group of patients with both methylated genes in a tumor (median survival - 4.9 months), and the difference was significant as compared with patients whose tumors had methylated GATA6 and unmethylated CASP8 (median survival - 9.7 months; log-rank test, $P=0.03$ ) (Figure $3 C$ ).

Table 2 Associations between demographic and clinical data of patients and methylation of five genes

\begin{tabular}{|c|c|c|c|c|c|c|c|c|c|c|c|c|c|c|c|c|}
\hline \multirow[t]{2}{*}{ Characteristic } & \multirow[t]{2}{*}{$n$} & \multicolumn{3}{|l|}{ MGMT } & \multicolumn{3}{|l|}{ GATA6 } & \multicolumn{3}{|l|}{$C D 81$} & \multicolumn{3}{|l|}{ CASP8 } & \multicolumn{3}{|l|}{ DR4 } \\
\hline & & U (\%) & M (\%) & $P$ & U (\%) & M (\%) & $P$ & U (\%) & M (\%) & $P$ & U (\%) & M (\%) & $P$ & U (\%) & M (\%) & $P$ \\
\hline \multicolumn{17}{|l|}{ Age } \\
\hline$<60$ years & 32 & 14.5 & 27.6 & 0.039 & 15.8 & 26.3 & 0.454 & 22.4 & 19.7 & 1.000 & 28.0 & 14.7 & 0.002 & 26.7 & 14.7 & 0.477 \\
\hline$\geq 60$ years & 44 & 34.2 & 23.7 & & 15.8 & 42.1 & & 31.6 & 26.3 & & 16.0 & 41.3 & & 32.0 & 26.7 & \\
\hline \multicolumn{17}{|l|}{ Sex } \\
\hline Male & 30 & 56.7 & 43.3 & 0.348 & 33.3 & 66.7 & 0.806 & 53.3 & 46.7 & 1.000 & 37.9 & 62.1 & 0.477 & 50.0 & 50.0 & 0.239 \\
\hline Female & 46 & 43.5 & 56.5 & & 30.4 & 69.6 & & 54.3 & 45.7 & & 47.8 & 52.2 & & 64.4 & 34.6 & \\
\hline \multicolumn{17}{|l|}{ Survival } \\
\hline$<36$ months & 62 & 56.5 & 43.5 & 0.006 & 30.6 & 69.4 & 0.775 & 54.8 & 45.2 & 0.774 & 37.7 & 62.3 & 0.035 & 53.2 & 46.8 & 0.061 \\
\hline$\geq 36$ months & 14 & 14.3 & 85.7 & & 35.7 & 64.3 & & 50.0 & 50.0 & & 71.4 & 28.6 & & 84.6 & 15.4 & \\
\hline
\end{tabular}

$\mathrm{n}$ - number of patients, $\mathrm{U}=$ unmethylated, $\mathrm{M}=$ methylated. 

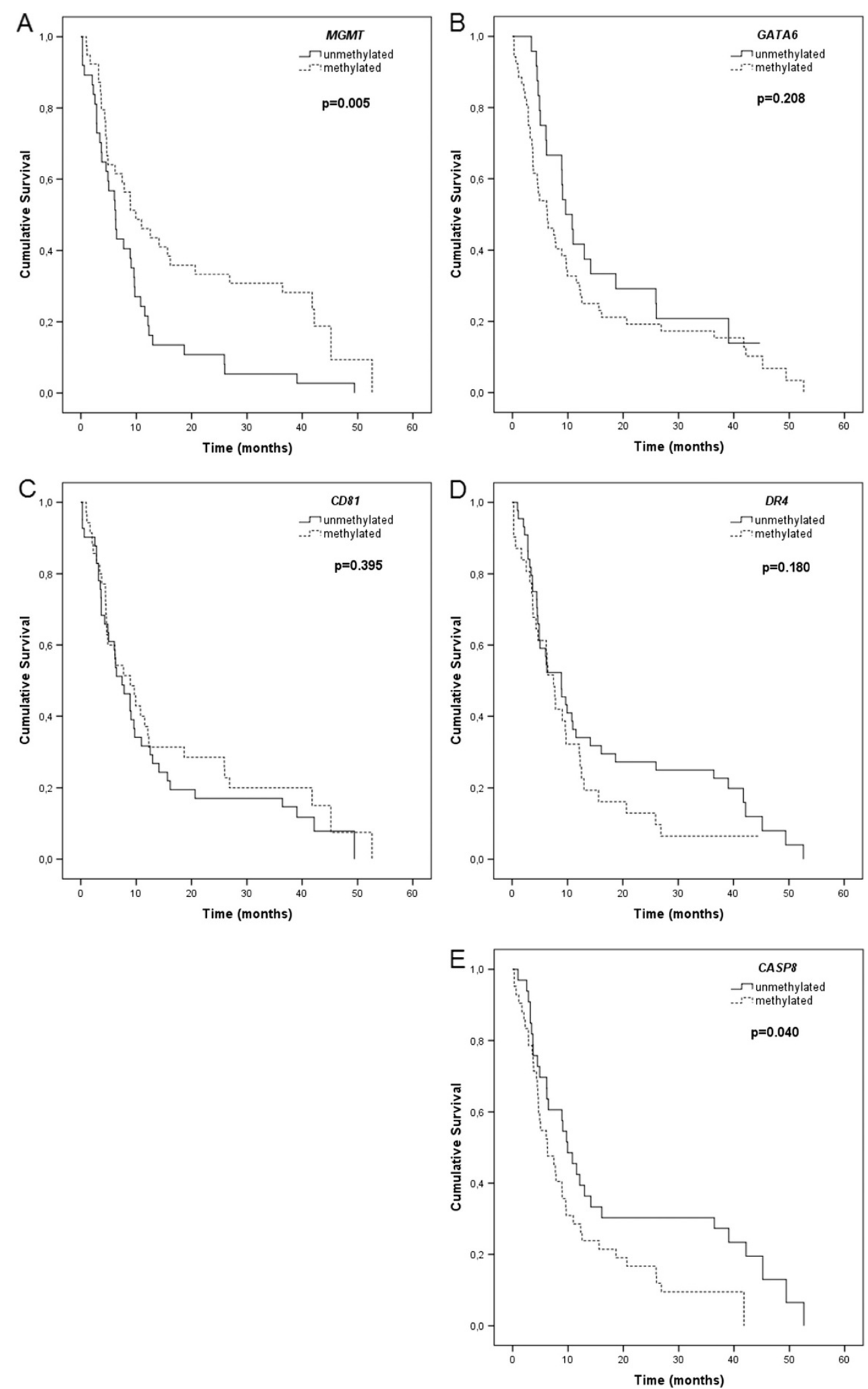

Figure 2 Kaplan-Meier cumulative survival (months) in glioblastoma patients. According to promoter methylation status of (A) MGMT gene (log-rank test, $\left.X^{2}=7.997, d f=1, P=0.005\right)$, (B) GATA6 gene (log-rank test, $\left.X^{2}=1.582, d f=1, P=0.208\right),(C)$ CD81 gene (log-rank test, $X^{2}=0.719, d f=1$, $P=0.395)$, (D) DR4 gene (log-rank test, $X^{2}=1.800, d f=1, P=0.180$ ), and (E) CASP8 gene (log-rank test, $\left.X^{2}=4.214 d f=1, P=0.040\right)$. 
Table 3 Kaplan-Meier survival function analysis in glioblastoma patients (log-rank test)

\begin{tabular}{|c|c|c|c|c|c|c|}
\hline \multirow[t]{2}{*}{ Variable } & \multirow{2}{*}{\multicolumn{2}{|c|}{$\mathrm{n}$}} & \multirow[t]{2}{*}{ Events } & \multicolumn{3}{|c|}{ Survival (months) } \\
\hline & & & & Median & $95 \% \mathrm{Cl}$ & $P$ \\
\hline \multirow[t]{2}{*}{ MGMT promoter methylation } & U & 37 & 37 & 6.2 & 4.6 to 7.9 & 0.005 \\
\hline & $\mathrm{M}$ & 39 & 32 & 9.9 & 4.2 to 15.7 & \\
\hline \multirow[t]{2}{*}{ GATA6 promoter methylation } & $U^{2}$ & 24 & 20 & 9.6 & 7.2 to 11.9 & 0.208 \\
\hline & $\bar{M} 5$ & 52 & 49 & 6.2 & 2.9 to 9.5 & \\
\hline \multirow[t]{2}{*}{ CD81 promoter methylation } & $U$ & 41 & 38 & 7.5 & 4.6 to 10.3 & 0.395 \\
\hline & $M$ & 35 & 31 & 8.9 & 4.6 to 13.3 & \\
\hline \multirow[t]{2}{*}{ DR4 promoter methylation } & $U$ & 44 & 40 & 8.9 & 4.9 to 12.8 & 0.174 \\
\hline & $\bar{M}$ & 31 & 29 & 7.5 & 5.6 to 9.3 & \\
\hline \multirow[t]{2}{*}{ CASP8 promoter methylation } & $U 3$ & 33 & 29 & 9.9 & 6.9 to 12.9 & 0.040 \\
\hline & $M$ & 42 & 39 & 6.2 & 3.3 to 9.2 & \\
\hline
\end{tabular}

$\mathrm{n}$ - total number of patients; $\mathrm{M}$ - methylated; $\mathrm{U}$ - unmethylated.

Univariate Cox analysis identified patient age, treatment modality, and methylation profile of the $M G M T$ and CASP8 promoters as independent predictive factors significantly associated with patient survival. Patients older than 60 years were more likely to survive shorter than their younger counterparts (hazards ratio [HR]: 1.06; 95\% CI: 1.04-1.09; $P=0.001)$. Moreover, patients who underwent treatment with $\mathrm{RT}+\mathrm{TMZ}$ had a $76 \%$ reduced risk of death (HR: 0.24, 95\% CI: 0.09-0.60; $P=0.003)$ as compared with patients treated with RT alone.

The methylation status of MGMT, CASP8, and GATA6 was of prognostic value for survival in a multivariate Cox model, when patient age and treatment were excluded (Table 4). The methylated MGMT promoter was associated with longer survival (HR: 0.45, 95\% CI: $0.27-0.76 ; P=0.002)$. Contrary, the methylated GATA6 and CASP8 promoters were found to be associated with shorter survival (HR: 1.77 95\% CI: 1.02-3.05; $P=0.041$ and HR: 1.84 95\% CI: 1.05-3.22; $P=0.033$, respectively).

When the patient sample was divided into two groups by age ( $<60$ years and $\geq 60$ years), multivariate Cox regression analysis showed that MGMT (HR: 0.15, 95\% CI: 0.05-0.42; $P=0.001)$ and GATA6 (HR: 2.78, 95\% CI: 1.01-7.65; $P=0.047$ ) were independent predictors for patient survival in younger patients' group, while there were no significant associations observed in older patients' group when adjusted for therapy (data not shown).

\section{Discussion}

Our study demonstrated that epigenetic alterations affecting multiple genes, which are important in several cell functions, such as DNA repair, cell migration and apoptosis, are a frequent event in glioblastoma. At least one of the five genes tested was methylated even in $97.3 \%$ of patients with glioblastoma, while only $2.7 \%$ of patients had no detectable methylation. Analysis identified 3 genes epigenetically deregulated in more than 50\% of glioblastomas: MGMT, GATA6, and CASP8. To our knowledge, only $M G M T$ has been previously widely described in glioblastomas, while the data on the epigenetic regulation of GATA6, CD81, DR4, and CASP8 in patient glioblastoma are scarce.

This study showed that the most frequently methylated gene was GATA6, a transcription factor, with a methylation frequency of $68.4 \%$. GATA6 is one of 6 members of the mammalian GATA family of transcription factors that regulates cell proliferation and differentiation and inhibits apoptosis [11]. Recently, it has been suggested as a tumor suppressor gene in tumors of the CNS with gene expression loss of $90 \%$ and promoter methylation of $30 \%-48 \%$ in glioblastomas [3,12-14]. It has been reported that loss of GATA6 results in
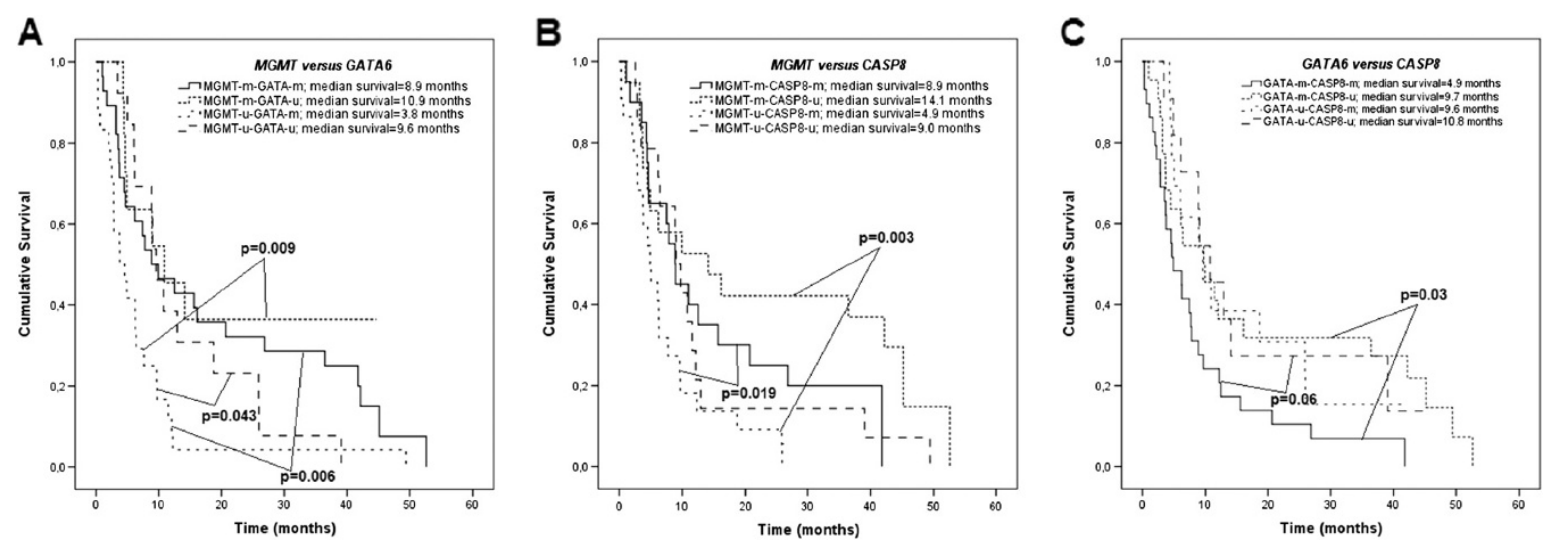

Figure 3 Kaplan-Meier cumulative survival (months) in glioblastoma patients plotted according to concomitant gene methylation patterns. (A) MGMT and GATA6 gene methylation status (log-rank test, $X^{2}=13.058, d f=3, P=0.005$ ), (B) MGMT and CASP8 gene methylation status (log-rank test, $\left.x^{2}=12.314, d f=3, P=0.006\right),(\mathbf{C})$ GATA6 and CASP8 gene methylation status (log-rank test, $x^{2}=7.712, d f=3, P=0.052$ ). 
Table 4 Multivariate Cox regression survival analysis for glioblastoma patients

\begin{tabular}{llll}
\hline Variable & \multicolumn{3}{l}{ Multivariate Cox regression } \\
\cline { 2 - 4 } & HR & $\mathbf{9 5 \% ~ C l}$ & $\mathbf{P}$ \\
\hline MGMT & 0.45 & $0.27-0.76$ & $\mathbf{0 . 0 0 2}$ \\
\hline GATA6 & 1.77 & $1.02-3.05$ & $\mathbf{0 . 0 4 1}$ \\
\hline CD81 & 0.69 & $0.41-1.15$ & 0.168 \\
\hline CASP8 & 1.84 & $1.05-3.22$ & $\mathbf{0 . 0 3 3}$ \\
\hline DR4 & 1.09 & $0.65-1.83$ & 0.755 \\
\hline
\end{tabular}

$\mathrm{HR}$ - hazard ratio, $\mathrm{Cl}$ - confidence interval.

enhanced astrocyte proliferation and transformation [14]. A decrease in GATA6 expression was observed in colon and ovarian carcinomas as well $[15,16]$.

The CD81 gene showed promoter methylation in $46.1 \%$ of tested glioblastomas in the current study. This gene is a member of the membrane-embedded tetraspanin superfamily, which was found to be silenced by methylation in multiple myeloma cell lines [7]. CD81 participates in several functions in a cell like adhesion and signal transduction [17]. Recent glioblastoma methylome studies have shown CD81 methylation rate of $54 \%[2,3]$.

Analysis of the methylation status of two proapoptotic genes, CASP8 and DR4, in our study revealed that these genes were methylated in $56 \%$ and $41 \%$ of glioblastomas, respectively. The inactivation of these genes by promoter methylation has been previously reported in osteosarcomas [18], melanomas [19], medulloblastomas [20], gastric carcinomas [9], and glioblastomas [3,13,21,22]. The frequency of DR4 methylation in glioblastomas varied from $25 \%$ to $70 \%$ in different studies [3,21,22]. In our series as compared with the above studies, a lower frequency of DR4 methylation was observed, and we hypothesize that the difference could be attributed to the heterogeneity of glioblastomas. In contrast to the findings of Elias et al. [21] and Hervouet et al. [13] who showed 10\%-30\% methylation of CASP8 in glioblastomas, in this panel more than half of tumors were methylated (56\%). The tendency of association between methylation of CASP8 and DR4 in glioblastomas was noted: co-methylation was observed in $28.4 \%$ (21/74) of tumors. A study carried out by Elias et al. [21] reported a smaller percentage of CASP8 and DR4 co-methylation in glioblastoma specimens (10\%). It is known that DR4 and CASP8 are factors affecting the nonmitochondrial apoptotic pathway, and the loss of DR4 expression (which was shown to be mediated by promoter methylation) attenuates apoptosis and is associated with the resistance of glioma cells to proapoptotic ligand therapy (known as TRAIL resistance) [21]. The importance of CASP8 in TRAIL resistance in gliomas has been reported as well [23], while the data of other studies have strongly suggested TRAIL sensitivity to be CASP8independent and DR4-specific [21].

Epigenetic silencing of the MGMT gene, encoding a DNA repair enzyme, has been recently found to be of predictive value in glioblastoma. In agreement with numerous studies where the methylation of MGMT was detected in approximately $40 \%-48 \%$ of primary glioblastomas $[1,2,24]$, our study showed a methylation frequency of $51 \%$. However, contrary to the study by Cecener et al. [12], this study found no significant association between the methylation of MGMT and GATA6 $(P>0.05)$ despite rather high comethylation of these genes (37\%).

Correlations with patient parameters showed MGMT and CASP8 gene methylation associations with patient age. Glioblastoma patients with methylated MGMT were significantly younger than those whose tumor lacked methylation $(P<0.05)$ and an opposite was observed for CASP8 $(P<0.01)$. Contrary, glioblastoma study of Cecener et al. [12] showed MGMT methylation association with older patient age ( $\geq 50$ years), while in the study of Weller et al. [24] MGMT methylation status was not associated with clinical parameters (age, extent of resection, Karnofsky performance score or treatment).

Several associations between survival and patients' characteristics were observed. Survival was strongly correlated with patients' age and treatment modality. In agreement with previous studies [24,25], it was observed that glioblastoma patients younger than 60 years and treated with RT + TMZ survived longer as compared with older and only RT-treated patients. Weller et al. [24] revealed age as a major therapy-independent factor in patient survival.

Cox regression analysis confirmed the methylation status of MGMT, GATA6, and CASP8, but not CD81 and $D R 4$, to be an independent factor for patient survival. Kaplan-Meier and Cox analysis showed the methylation status of MGMT to be significantly related to patient outcome. In agreement with previous studies $[1,3,26]$ reporting the associations between MGMT methylation status and patient survival, our study showed that patients with methylated MGMT were more likely to survive longer and were at lower risk of death than those with the unmethylated gene. After dividing the patient sample into the groups by age ( $<60$ years vs. $\geq 60$ years), methylated MGMT remained a significant independent predictor of survival among patients aged less than 60 years. Furthermore, we confirmed significant association between the methylation profile of MGMT and treatment modality: in the group of patients treated with RT + TMZ, patients with methylated $M G M T$ survived significantly longer than those with unmethylated gene promoter (median survival, 41.4 vs. 15.1 months) (data not shown).

In line with findings of the study by Martinez et al. [22], associations between the methylation of CASP8 
and survival in our study showed gene methylation being an important factor for worse outcome of patients. Patients with unmethylated CASP8 as a favorable genotype had prolonged survival as compared with patients having tumors with methylated CASP8. Although CASP8 may play an essential role in apoptosis induced by chemotherapeutic agents and radiation therapy $[27,28]$, our study showed only a trend toward significant associations between the methylation status of CASP8 and survival of the patients treated with RT, and no associations in the group of the patients treated with RT + TMZ (data not shown).

Survival among patients with the methylated vs. unmethylated GATA6 gene differed significantly at early postoperative period (3-month survival, 100\% vs. 75\%). Cox regression analysis demonstrated CASP8 and GATA6 as independent predictors for patient survival. Furthermore, GATA6 became independent predictor for survival in younger patient group. Contrary to our results, recently it have been reported no relationship of GATA6 [12] and CASP8 [13] methylation status with survival in patients with glioblastoma. In agreement with the methylome study by Martinez et al. [3], where the significance of GATA6 methylation in patient survival has been shown for the first time, our results suggest that the methylation of GATA6 is a frequent event and highly important for survival of patients with glioblastoma.

\section{Conclusions}

The current study reveals new and important information on MGMT, GATA6 and CASP8 promoter methylation in glioblastoma. GATA6 methylation occurred at a highest rate. Patient age, treatment regimen, MGMT, GATA6 and CASP8 methylation status were significantly associated with patient survival. MGMT and GATA6 were independent predictors for patient survival in younger patients' group when adjusted for therapy. To further evaluate validation of the methylation profile of these genes is necessary for understanding their role in gliomagenesis and potential as GBM markers.

\section{Competing interests}

The authors are not aware of any biases that might be perceived as affecting the objectivity of this article.

\footnotetext{
Acknowledgments

This research was funded by a grant (No. LIG - 17/2010) from the Research Council of Lithuania. We are very thankful to master students, Mr. Giedrius Steponaitis and Ms. Dalia Gedmintaite, from the Department of Biology of Vytautas Magnus university of Kaunas, Lithuania, for perfect technical help in gene methylation analysis.
}

\section{Author details}

${ }^{1}$ Laboratory of Neurooncology and Genetics, Neuroscience Institute, Medical Academy, Lithuanian University of Health Sciences, Eiveniu str. 4, Kaunas, LT 50009, Lithuania. ${ }^{2}$ Department of Physics, Mathematics, and Biophysics,
Medical Academy, Lithuanian University of Health Sciences, Eiveniu str. 4, Kaunas, LT 50009, Lithuania.

\section{Authors' contributions}

DS, PV, and VA generated an idea. DS did a part of DR4, MGMT and GATA6 MSP analysis, statistical analysis and wrote a paper. PV did CD81 and CASP8 methylation analysis. VS did all statistical analysis. AT, KS, PVD generated an idea, gathered postoperative glioblastoma tissue and patient data.

Received: 13 December 2011 Accepted: 6 June 2012

Published: 6 June 2012

\section{References}

1. Hegi ME, Diserens AC, Gorlia T, Hamou MF, de Tribolet N, Weller M, Kros JM, Hainfellner JA, Mason W, Mariani L, Bromberg JE, Hau P, Mirimanoff RO, Cairncross JG, Janzer RC, Stupp R: MGMT gene silencing and benefit from temozolomide in glioblastoma. N Engl J Med 2005, 352:997-1003.

2. Laffaire J, Everhard S, Idbaih A, Criniere E, Marie Y, de Reynies A, Schiappa R, Mokhtari K, Hoang-Xuan K, Sanson M, Delattre JY, Thillet J, Ducray F: Methylation profiling identifies 2 groups of gliomas according to their tumorigenesis. Neuro Oncol 2011, 13:8498.

3. Martinez $R$, Martin-Subero Jl, Rohde $V$, Kirsch M, Alaminos M, Fern_Indez AŁF, Ropero S, Schackert G, Esteller M: A microarray-based DNA methylation study of glioblastoma multiforme. Epigenetics 2009, 4:255-264.

4. Noushmehr H, Weisenberger DJ, Diefes K, Phillips HS, Pujara K, Berman BP, Pan F, Pelloski CE, Sulman EP, Bhat KP, Verhaak RG, Hoadley KA, Hayes DN, Perou CM, Schmidt HK, Ding L, Wilson RK, Van Den Berg D, Shen $H$, Bengtsson H, Neuvial P, Cope LM, Buckley J, Herman JG, Baylin SB, Laird PW, Aldape K, Cancer Genome Atlas Research Network: Identification of a CpG island methylator phenotype that defines a distinct subgroup of glioma. Cancer Cell 2010, 17:510-522.

5. Louis DN, Ohgaki H, Wiestler OD, Cavenee WK (Eds): WHO Classification of tumours of the central nervous system. Lyon: IARC; 2007.

6. Esteller M, Hamilton SR, Burger PC, Baylin SB, Herman JG: Inactivation of the DNA repair gene O6-methylguanine-DNA methyltransferase by promoter hypermethylation is a common event in primary human neoplasia. Cancer Res 1999, 59:793-797.

7. Drucker L, Tohami T, Tartakover-Matalon Zismanov, Shapiro H, Radnay J, Lishner M: Promoter hypermethylation of tetraspanin members contributes to their silencing in myeloma cell lines. Carcinogenesis 2006, 27:197-204

8. Guo M, Akiyama Y, House MG, Hooker CM, Heath E, Gabrielson E, Yang SC, Han Y, Baylin SB, Herman JG, Brock MV: Hypermethylation of the GATA genes in lung cancer. Clin Cancer Res 2004, 10:7917-7924.

9. Lee KH, Lim SW, Kim HG, Kim DY, Ryu SY, Joo JK, Kim JC, Lee JH: Lack of death receptor 4 (DR4) expression through gene promoter methylation in gastric carcinoma. Langenbecks Arch Sur 2009, 394:661-670.

10. van Noesel MM, van Bezouw S, Salomons GS, Voute PA, Pieters R, Baylin SB, Herman JG, Versteeg R: Tumor-specific down-regulation of the tumor necrosis factor-related apoptosis-inducing ligand decoy receptors DcR1 and DcR2 is associated with dense promoter hypermethylation. Cancer Res 2002, 62:2157-2161.

11. Shureiqi I, Jiang W, Fischer SM, Xu X, Chen D, Lee JJ, Lotan R, Lippman SM: GATA-6 transcriptional regulation of 15-lipoxygenase-1 during NSAID-induced apoptosis in colorectal cancer cells. Cancer Res 2002, 62:1178-1183.

12. Cecener G, Tunca B, Egeli U, Bekar A, Tezcan G, Erturk E, Bayram N, Tolunay S: The Promoter Hypermethylation Status of GATA6, MGMT, and FHIT in glioblastoma. Cell Mol Neurobiol 2012, 32:237-244.

13. Hervouet $E$, Vallette FM, Cartron PF: Impact of the DNA methyltransferases expression on the methylation status of apoptosis-associated genes in glioblastoma multiforme. Cell Death Dis 2010, 1:e8.

14. Kamnasaran D, Qian B, Hawkins C, Stanford WL, Guha A: GATA6 is an astrocytoma tumor suppressor gene identified by gene trapping of mouse glioma model. Proc Natl Acad Sci USA 2007, 104:8053-8058.

15. Caslini C, Capo-chichi CD, Roland IH, Nicolas E, Yeung AT, Xu XX: Histone modifications silence the GATA transcription factor genes in ovarian cancer. Oncogene 2006, 25:5446-5461. 
16. Haveri H, Westerholm-Ormio M, Lindfors $K$, Maki M, Savilahti E, Andersson L, Heikinheimo M: Transcription factors GATA-4 and GATA-6 in normal and neoplastic human gastrointestinal mucosa. BMC Gastroenterol 2008, 8:9.

17. Levy S, Todd SC, Maecker HT: CD81 (TAPA-1): a molecule involved in signal transduction and cell adhesion in the immune system. Annu Rew Immunol 1998, 16:89-109.

18. Sadikovic B, Yoshimoto M, Chilton-Macneill, Thorner P, Squire JA, Zielenska M: Identification of interactive networks of gene expression associated with osteosarcoma oncogenesis by integrated molecular profiling. Hum Mol Genet 2009, 18:1962-1975.

19. Bae SI, Cheriyath V, Jacobs BS, Reu FJ, Borden EC: Reversal of methylation silencing of Apo2L/TRAIL receptor 1 (DR4) expression overcomes resistance of SK-MEL-3 and SK-MEL-28 melanoma cells to interferons (IFNs) or Apo2L/TRAIL. Oncogene 2008, 27:490-498.

20. Aguilera DG, Das CM, Sinnappah-Kang ND, Joyce C, Taylor PH, Wen S, Hasselblatt M, Paulus W, Fuller G, Wolff JE, Gopalakrishnan V: Reactivation of death receptor 4 (DR4) expression sensitizes medulloblastoma cell lines to TRAIL. J Neurooncol 2009, 93:303-318.

21. Elias A, Siegelin MD, Steinmüller A, von Deimling A, Lass U, Korn B, Mueller W: Epigenetic silencing of death receptor 4 mediates tumor necrosis factor-related apoptosis-inducing ligand resistance in gliomas. Clin Cancer Res 2009, 15:5457-5465.

22. Martinez R, Setien F, Voelter C, Casado S, Quesada MP, Schackert G, Esteller $\mathrm{M}: \mathrm{CpG}$ island promoter hypermethylation of the pro-apoptotic gene caspase-8 is a common hallmark of relapsed glioblastoma multiforme. Carcinogenesis 2007, 28:1264-1268.

23. Fulda S, Küfer MU, Meyer E, van Valen F, Dockhorn-Dworniczak B, Debatin KM: Sensitization for death receptor- or drug-induced apoptosis by reexpression of caspase-8 through demethylation or gene transfer. Oncogene 2001, 20:5865-5877.

24. Weller M, Felsberg J, Hartmann C, Berger H, Steinbach JP, Schramm J, Westphal M, Schackert G, Simon M, Tonn JC, Heese O, Krex D, Nikkhah G, Pietsch T, Wiestler O, Reifenberger G, von Deimling A, Loeffler M: Molecular predictors of progression-free and overall survival in patients with newly diagnosed glioblastoma: a prospective translational study of the German Glioma Network. J Clin Oncol 2009, 27:5743-5750.

25. Das $P$, Puri $T$, Jha P, Pathak P, Joshi N, Suri V, Sharma MC, Sharma BS, Mahapatra AK, Suri A, Sarkar C: A clinicopathological and molecular analysis of glioblastoma multiforme with long-term survival. J Clin Neurosci 2011, 18:66-70.

26. Etcheverry A, Aubry M, de Tayrac M, Vauleon E, Boniface R, Guenot F, Saikali S, Hamlat A, Riffaud L, Menei P, Quillien V, Mosser J: DNA methylation in glioblastoma: impact on gene expression and clinical outcome. BMC Genomics 2011, 11:701.

27. Fulda S, Sieverts H, Friesen C, Debatin KM: The CD95 (APO-1/Fas) system mediates drug-induced apoptosis in neuroblastoma cells. Cancer Res 1997, 57:3823-3829.

28. Rehemtulla A, Hamilton CA, Chinnaiyan AM, Dixit VM: Ultraviolet radiationinduced apoptosis is mediated by activation of CD-95 (Fas/APO-1). J Biol Chem 1997, 272:25783-25786.

doi:10.1186/1471-2407-12-218

Cite this article as: Skiriute et al: MGMT, GATA6, CD81, DR4, and CASP8 gene promoter methylation in glioblastoma. BMC Cancer 2012 12:218.

\section{Submit your next manuscript to BioMed Central and take full advantage of:}

- Convenient online submission

- Thorough peer review

- No space constraints or color figure charges

- Immediate publication on acceptance

- Inclusion in PubMed, CAS, Scopus and Google Scholar

- Research which is freely available for redistribution 